\title{
SANTAMARÍA Daniel J., Chaco Gualamba. Del monte salvaje al desierto ilustrado
}

\section{Federico Bossert}

\section{OpenEdition}

\section{Journals}

\section{Edición electrónica}

URL: https://journals.openedition.org/jsa/12438

DOI: $10.4000 /$ jsa. 12438

ISSN: $1957-7842$

\section{Editor}

Société des américanistes

\section{Edición impresa}

Fecha de publicación: 31 diciembre 2012

Paginación: 273-276

ISSN: 0037-9174

\section{Referencia electrónica}

Federico Bossert, "santamaría Daniel J., Chaco Gualamba. Del monte salvaje al desierto ilustrado»,

Journal de la Société des américanistes [En línea], 98-2 | 2012, Publicado el 05 junio 2013, consultado el 03 septiembre 2022. URL: http://journals.openedition.org/jsa/12438 ; DOl: https://doi.org/10.4000/jsa. 12438

Este documento fue generado automáticamente el 3 septiembre 2022.

All rights reserved 


\title{
SANTAMARÍA Daniel J., Chaco Gualamba. Del monte salvaje al desierto ilustrado
}

\author{
Federico Bossert
}

\section{REFERENCIA}

SANTAMARÍA Daniel J., Chaco Gualamba. Del monte salvaje al desierto ilustrado, Cuadernos del Duende, Jujuy, 2007, $191 \mathrm{p}$.

1 A pesar de su título, que evoca el monumental tratado del Padre Lozano - la Descripción Corográfica del Gran Chaco Gualamba - esta obra no constituye una introducción general a la historia del Chaco, por varios motivos. En primer lugar, por el orden de su exposición, que elude la narración cronológica o el desarrollo temático progresivo y concentra la discusión en algunos pocos tópicos muy precisos: la presencia portuguesa en el Chaco, la cuestión del robo de ganado, la evolución de las expediciones punitivas, las visiones estatales sobre el indígena. En segundo lugar, porque estas temáticas puntuales son abordadas de un modo muy poco lineal, a través de una acumulación de menciones a documentos temporal y geográficamente dispersos, entre las cuales un lector poco familiarizado con la historia del Chaco difícilmente podría orientarse. En tercer lugar, porque, si bien dedica un sumario capítulo a la descripción de las naciones chaqueñas, su principal interés no está en ellas per se, sino en las relaciones que mantenían con sus vecinos españoles, portugueses y mestizos. En cuarto lugar, porque, si bien en principio no restringe su análisis a límites temporales precisos, la obra está claramente concentrada en el siglo xviII; de hecho, el autor parece considerar que durante este siglo las relaciones entre las sociedades chaqueñas y coloniales cristalizaron en formas bien definidas, que iban a desaparecer rápidamente con las guerras de independencia. Por último, porque, si bien largas páginas se dedican al Chaco boreal (la discusión sobre las entradas portuguesas desde Cuiabá, o las muchas menciones a los mbayá), el grueso del 
libro está dedicado al Chaco central y austral, es decir, a la región al sur del río Pilcomayo. De hecho, uno de sus principales atractivos es que el grueso de la documentación provenga de archivos argentinos (el Archivo General de la Nación y diversos archivos provinciales del noroeste argentino, provenientes de la vieja gobernación del Tucumán colonial); esto concentra su análisis en la frontera chaqueña del Tucumán - mucho menos conocida que las de Asunción o Charcas - y, así, nos presenta hechos mucho menos transitados por la historiografía chaqueña.

2 Delineados los intereses generales de la obra, pasemos a la revisión de sus contenidos. En cuanto al primer capítulo, es realmente curioso que una obra dedicada al Chaco comience en la frontera portuguesa, exponiendo las condiciones económicas de Cuiabá en el siglo xVIII y postulando que esta ciudad alimentaba su comercio de esclavos con indígenas chaqueños. A partir de esto, Santamaría procura demostrar - a través de menciones elípticas en los documentos a bandeirantes y contrabandistas siempre esquivos -, que los portugueses llegaron a dominar una ruta diagonal que atravesaba el Chaco en dirección sudoeste, desde Cuiabá hasta el alto Pilcomayo, y que en los bordes hispánicos trabaron relaciones con los tobas - relaciones que los documentos sólo permiten imaginar.

3 Las siguientes páginas reúnen algunas generalidades sobre el Chaco y sus pueblos; más que nada, se ocupan de presentar al múltiple grupo que protagoniza el grueso del libro: los toba, guerreros ecuestres en permanente expansión, enemigos declarados de la administración colonial en todas las costas del Chaco. El siguiente capítulo trata la cuestión del robo de ganado y las economías de las sociedades chaqueñas. En cuanto al robo de ganado, el autor postula que el consumo de carne vacuna se había vuelto uno de los principales alimentos de los pueblos ecuestres, quienes en consecuencia organizaban su vida económica en torno de la adquisición de ganado. Ante todo, conocían los hábitos del ganado " alzado ", fugitivo o salvaje, y procuraban encontrarlo y controlarlo; así se permite imaginar que mucho del ganado "robado" que denunciaban los españoles consistía en realidad en estos animales errantes, perdidos, sin dueño verdadero. Otras veces conseguían las vacas por medio del comercio, a cambio de caballos robados a los " apóstatas ». Y, por último, recurrían con frecuencia al malón, al ataque a haciendas españolas para apropiarse de sus vacas y sus caballos. El malón, dice el autor, era ciertamente un episodio de retribución en la guerra contra las potencias coloniales que avanzaban sobre el territorio indígena; pero, como recurso económico, seguramente no era el preferido. Santamaría impugna la imagen colonial del indígena - y, en particular, del toba- como un ser inevitablemente violento, con quien era imposible la convivencia. Vincula estos prejuicios coloniales con ciertas conclusiones de la etnografía y la etnohistoria, que a menudo han recurrido a la expresión « ethos guerrero » de las sociedades chaqueñas para resumir los imperativos éticos que guiaban la guerra episódica entre distintos grupos étnicos, y por lo tanto procura refutar también estas ideas. Para eso, postula que la guerra contra el blanco por los recursos (el malón), lejos de la fatalidad o los imperativos, era un recurso extremo, una empresa siempre riesgosa a la que sólo se apelaba en graves circunstancias - hambrunas, sequías, reducción de ríos, etc.: "Sin ninguno de estos requisitos, los toba prefieren el expediente pacífico del conchabo o de la aproximación a las misiones que ellos saben son verdaderos mercados de tránsito » (p. 79).

4 El siguiente capítulo, que trata « las guerras del Chaco », se dedica en buena parte a una ordenada exposición de las políticas respecto de los chaqueños desarrolladas por las 
sucesivas administraciones del Tucumán durante el siglo xviII. Se reseñan aquí - en muchos casos apenas se mencionan - muchas de las entradas punitivas, batallas, alianzas interétnicas, fundaciones de fuertes y reducciones que compusieron la guerra contra los tobas durante la primera mitad del siglo. Luego se exponen las políticas llevadas a cabo por los gobernadores Martínez de Tineo (expansión de los fuertes-reducciones), Fernández Campero (proyecto de relocalización de los indígenas) y Matorras (el más grande intento del siglo por trabar tratados de paz con los tobas y mocovíes del Chaco central).

El último capítulo, dedicado a "los discursos sobre el indio", circunscribe las características y los efectos de las tres principales ideologías del siglo respecto del indígena: la conservadora, la asistencialista, y la liberal-ilustrada. El primer discurso es representado en el Tucumán por el « partido de los hacendados », el patriciado mercantil que no deseaba la paz con el indio y abogaba por la relocalización y el restablecimiento de las encomiendas. Una de sus manifestaciones era el trabajo forzado de indígenas en las haciendas; otra era la esclavitud de la mujer indígena como servidumbre doméstica, convertidas en auténticas mercancías durante todo el siglo xviII; la última, y fundamental, la reducción de los indígenas en misiones-fuertes, donde eran controlados, sedentarizados y desde donde podían ser enrolados con facilidad para el trabajo en las haciendas vecinas. El segundo discurso, el asistencialista, de inspiración jesuita, encontró su mejor expresión en el proyecto del gobernador Matorras; defendía la estrategia de ganar la buena voluntad de los indígenas por medio de dádivas, y fracasó rápidamente. El tercer discurso, de consecuencias más extensas y perennes, provenía de cierta Ilustración católica y sostenía que los indígenas ciertamente poseían una racionalidad, que la educación de los misioneros sacaba a la luz, y que por lo tanto debían cultivar sus tierras e integrarse al mercado colonial. El autor discute en este apartado una larga serie de fenómenos relacionados, en mayor o menor medida, con el funcionamiento de un sistema mercantil en el Chaco: el funcionamiento de los fuertes como mercados, el tributo indígena sustraído del pago por su trabajo en las haciendas, los planes de rutas transchaqueñas, y la presencia de « apóstatas », «forajidos » o « mamelucos » dedicados al contrabando. En estos fenómenos, procura ver los rastros de un comercio de larga distancia que, con o sin la participación de los indígenas, incluía efectivamente la región chaqueña en el sistema mercantil colonial. De ahí su conclusión: « El Chaco no divide dos mundos, dos culturas o dos civilizaciones, sino que forma un espacio a partir del cual los ganaderos españoles, mestizos o indios organizan su comercio con mayor libertad, evadiendo impuestos, vendiendo a mejores precios, desembarazados de la presión que sobre ellos ejerce la concentración de oferta en las ciudades » (p. 176).

6 En efecto, a criterio de Santamaría, las historias del Chaco en el siglo XVIII que presentan ese espacio como un macizo impenetrable, y a sus pueblos como guerreros irredimibles, parten de una confusión y reproducen sin advertirlo la noción colonial de «frontera ». Este pequeño y denso libro - como otros tantos escritos del autor - se edifica sobre una noción diferente del Chaco histórico, enfatizando los encuentros permanentes, los pactos y comercios que existían en sus bordes y los circuitos mercantiles ilegales que tenían lugar en su interior. Es decir, una imagen que refuta la de un prístino reservorio étnico mantenido hasta finales del siglo XIX, un Chaco atravesado por múltiples influencias y mestizajes, una escena histórica compuesta por blancos e indígenas a la vez, donde la guerra, lejos de los imperativos categóricos, es ante todo el fracaso de la negociación pacífica y el comercio. 


\section{AUTORES}

\section{FEDERICO BOSSERT}

CONICET, Argentina 